\title{
A glimpse into the training of the next generation of physicians
}

Educating Physicians: A Call for Reform of Medical School and Residency

Molly Cooke, David M. Irby and Bridget C. O'Brien

Jossey-Bass; 2010

I am now more than 10 years out of residency, and I find that I am increasingly tempted by the distasteful habit that afflicts academic physicians: making comparisons between the (exemplary) training I underwent years ago and the (deplorably deteriorated) state of medical education today. Attending staff cast a suspicious eye at residents leaving "early" after being on call, and it is hard to resist commenting to one another on how different it was back when (dedicated) residents such as ourselves worked 36 hours straight without sleeping. Of course, there were (glaringly obvious) problems with this (bizarre and inhumane) form of learning, but darn it all, it turned out doctors who could treat patients without referring to an electronic hand-held device every five minutes. How things have changed.

This is not a new complaint. When I was a medical student, one of my preceptors bemoaned the fact that house staff no longer resided in the hospital full time the way he did when he was a student. But it may be that the degree and rate of change is greater now than it has been in a century. Ideological and societal shifts have led to a dramatic rethinking of how physicians should be trained. The changes in the context and direction of medical education are discussed in this book.

Educating Physicians was published by the Carnegie Foundation in 2010 to mark the centenary of Medical Education in the United States and Canada Bulletin Number Four, by Abraham Flexner, which appeared in 1910. Often referred to as the Flexner Report, the original document had a significant and lasting effect on medical education in North America.

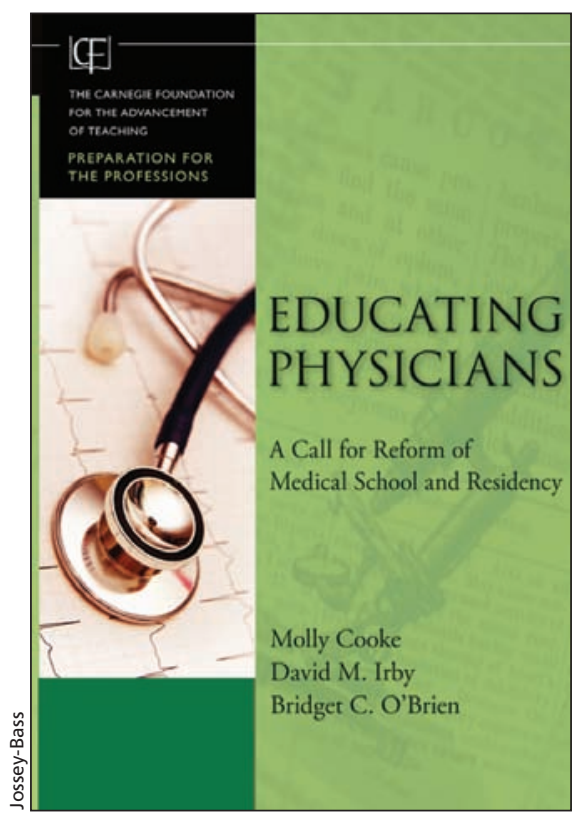

In a time when medical schools were unregulated and of inconsistent quality, the Flexner Report led to the closure of many of them. Flexner advocated the model of a university-based program emphasizing a two-year period of training in basic sciences followed by clinical experience. ${ }^{1}$ Generations of North American medical students have been trained in institutions and programs that were shaped by the Flexner's report, and our conceptions of what is "foundational" in medical training is so influenced by his vision that it is easy to mistake his ideas for received truth.

Whereas Flexner visited every medical training site in North America, Cooke, Irby and O'Brien chose a sample of 11 American medical schools and teaching hospitals. In contrast with the Flexner Report, Educating Physicians addresses a medical education system that is formalized, regulated and accredited. While it is difficult to summarize all of the book's recommendations, the biggest change is to ask "What should medical students be like?" rather than "What should they know?" The focus on the scientific basis of medicine, which Flexner had emphasized, has shifted. One of the areas that the authors say has been previously overlooked in medical training is "the formation of a professional identity with a moral and ethical core of service and responsibility." (p.ix) In addition, they emphasize teaching skills for self-management, advocacy, and reflection, and inculcating values such as empathy and commitment to excellence. Competencybased teaching and assessment, early clinical exposure, and flexible training schedules are among the directions that are espoused. While the book focuses on the American system, the trends and influences are sufficiently similar that the majority of the book is directly applicable to the Canadian context.

Educating Physicians provides an overview of the current thinking in a manner that is accessible to the average doctor. It will doubtless be very influential, although perhaps not to the degree that the Flexner's report was a century ago. With all the reading that is necessary for physicians to do to keep current on advances in patient care, the clinical faculty who teach medical students and residents do not necessarily have a great deal of time to spend reading the latest medical education literature. Unfortunately, I have a suspicion that many of the attending staff who are already bemoaning the state of medical education today may not find it particularly comforting reading. But if you want to read one book this year to see how the next generation of doctors is going be trained, then Educating Physicians is the one you should read.

\section{Lara Hazelton MD}

Psychiatrist

Halifax, NS

\section{Reference}

1. Duffin J. Did Abraham Flexner spark the founding of CMAJ? CMAJ 2011;183:811-3.

CMAJ 2012. DOI:10.1503/cmaj.110825 